\title{
A METHOD OF EVALUATING PERINATAL MORTALITY RISK
}

\author{
BY \\ MARTIN S. FELDSTEIN* \\ Nuffield College, Oxford
}

The risk of perinatal mortality is the resultant of a large number of biological and social influences. Age, parity, social class, height, and past obstetric history are only some of the factors that should be taken into account in assessing the risk for any particular woman. This raises a difficult problem. In several factors she may be below average in risk while in others she is above average. She may, for example, be in Social Class I, but be 38 years old and having her fourth child. How should her risk be compared with that of another woman who is in Social Class V but is 23 years old and having her third child?

Assessing the risk for any case requires estimating the specific effect of each factor and weighing these together to arrive at an overall value. This paper reports the development of a multiple regression method for evaluating perinatal mortality risks and identifying cases most likely to benefit from intensive antenatal care or hospital delivery.

The data used for this study was collected by the Perinatal Mortality Survey (Butler and Bonham, 1963). During one week in March, 1958, the Survey directed by Dr Neville Butler obtained information on 16,994 single births, some 98 per cent. of all births during the week. Perinatal deaths (defined to include the entire 4-week neonatal period) of babies born during March, April, and May were also recorded. The 7,117 survey deaths represent an estimated 94 per cent. of all deaths at risk.

\section{Statistical Evaluation Models}

The simple model shown in Table $I$ indicates the basic features of the statistical evaluation process.

A model such as this would be used to assess a woman's perinatal mortality risk if age and parity were the only available information. The risk of a particular age-parity combination is the sum of the age effect (A-value) and the parity effect (P-value);

* Lecturer in Public Finance, Oxford University; Fellow in Economics, Nuffield College, Oxford.
TABLE I

FACTOR VALUES FOR ASSESSING PERINATAL MORTALITY RISK WITH MATERNAL AGE AND PARITY INFORMATION*

\begin{tabular}{c|c|c|c}
\hline $\begin{array}{c}\text { Age (yrs) } \\
\text { (1) }\end{array}$ & $\begin{array}{c}\text { A Value } \\
\text { (2) }\end{array}$ & $\begin{array}{c}\text { Parity } \\
\text { (3) }\end{array}$ & $\begin{array}{c}\text { P Value } \\
\text { (4) }\end{array}$ \\
\hline$<20$ & $43 \cdot 33$ & 0 & $68 \cdot 37$ \\
$20-$ & $30 \cdot 92$ & 1 & $33 \cdot 12$ \\
$25-$ & $33 \cdot 21$ & 2 and 3 & $53 \cdot 19$ \\
$30-$ & $51 \cdot 70$ & $4+$ & $87 \cdot 28$ \\
$35-$ & $75 \cdot 96$ & & \\
$40+$ & $138 \cdot 29$ & & \\
\hline
\end{tabular}

- Risk $=\mathbf{A}+\mathbf{P}$. Average population risk of 100 corresponds to perinatal mortality rate of $33 \cdot 58$ per 1,000 births.

the scale of these factor values has been chosen so that a risk of 100 corresponds to the average perinatal mortality rate of 33.58 perinatal deaths per 1,000 births. Thus a woman aged 38 having her fourth child has a risk of $75 \cdot 96+53 \cdot 19=129 \cdot 15$. With this model one would also assess the risk of a 23-year-old para- 2 mother as $30 \cdot 92+53 \cdot 19=84 \cdot 11$.

Two problems arise in considering the accuracy of this method: are the factor values used in the model those which will give the most accurate evaluations, and is the model an appropriate one?

FACtor VAlues.-The values used in the model are derived from observations during a period in 1958. To the extent that relationships between sociobiological factors and perinatal mortality have changed since then, values based on the sample data will be inaccurate. This is a general problem that arises whenever we try to learn from past experience. In the absence of more recent data of comparable scope, and in the belief that the forces which influence perinatal mortality change only gradually, we are justified in using the survey data.

The factor values have been calculated by a form of least squares multiple regression analysis, in which all the variables are binary. Each variable 135 
represents a single sub-class of a factor, taking the value 1 if the mother falls into that sub-class and zero otherwise. Similarly, the dependent variable is 1 if the birth results in a perinatal death and zero otherwise. The method of calculation is explained more fully in the Appendix.

The use of binary variables frees us from any arbitrary assumptions about the form of the relationship between the factor and perinatal mortality risk. It also allows us to consider factors which are qualitative and cannot be scaled (e.g. region of residence). Although an element of arbitrariness enters in fixing the divisions of a quantitative variable or defining the sub-classes of a qualitative variable, the use of modern computing facilities will allow a sufficiently large number of classes so that this should not be an important problem. The binary character of the dependent variable violates the least square assumption of homoskedasticity; the variance of the error term associated with any observation will be approximately proportional to that individual's risk. The resulting parameter estimates, although inefficient, are nevertheless unbiased. Although a two-stage procedure producing approximate generalized least squares estimates would be possible, the sample size of nearly 17,000 makes the gain in efficiency of limited importance (see Appendix).

Choice of Models.-More serious problems are raised in the selection of appropriate evaluation models. The model presented above is obviously too simple, omitting a number of important factors that influence perinatal mortality risk. Fortunately, the method of calculating factor values can be extended to models which contain a large number of factors. Electronic computers make possible the long and complicated calculations that are needed when ten or even more factors are included. The survey data is being prepared in a form that will permit the consideration of more than thirty factors which might assist in the evaluation of risk.

An example of a slightly more complex model is shown in Table II. These age, parity, and social class factor values permit us to evaluate and compare more accurately the risks of the two cases described above. A woman in Social Class I, aged 38 years and para-3, would have a risk of $172 \cdot 19-19 \cdot 57-44 \cdot 97=$ $107 \cdot 65$, while another who is in Social Class V, aged 23 and para-2, would have a risk of 224.01 $71 \cdot 53-44 \cdot 97=104 \cdot 51$. Thus both women are slightly above average in risk and not very different from each other. The contrast between these results and those obtained when age and parity are considered without social class $(129 \cdot 15$ and $89 \cdot 11)$ indicates the increased accuracy obtained by develop-
TABLE II

FACTOR VALUES FOR ASSESSING PERINATAL MORTALITY RISK WITH MATERNAL AGE, PARITY, AND SOCIAL CLASS INFORMATION*

\begin{tabular}{|c|c|c|c|c|c|}
\hline $\begin{array}{c}\text { Age } \\
\text { (yrs) } \\
(1)\end{array}$ & $\begin{array}{c}\text { A Value } \\
\text { (2) }\end{array}$ & $\begin{array}{l}\text { Parity } \\
\text { (3) }\end{array}$ & $\begin{array}{c}\text { P Value } \\
\text { (4) }\end{array}$ & $\begin{array}{c}\text { Social } \\
\text { Class of } \\
\text { Husband } \\
(5)\end{array}$ & $\begin{array}{c}\text { S Value } \\
(6)\end{array}$ \\
\hline $\begin{array}{c}<20 \\
20- \\
25- \\
30- \\
35- \\
40+\end{array}$ & $\begin{array}{l}-66.86 \\
-71.53 \\
-64.71 \\
-44.58 \\
-19.57 \\
+41.15\end{array}$ & $\begin{array}{l}0 \\
1 \\
2 \text { and } 3 \\
4+\end{array}$ & $\begin{array}{l}-25 \cdot 98 \\
-61 \cdot 80 \\
-44.97 \\
-16.37\end{array}$ & $\begin{array}{l}\text { I and II } \\
\text { III } \\
\text { IV } \\
\text { V } \\
\text { No } \\
\text { husband }\end{array}$ & $\begin{array}{r}+172.19 \\
+191.90 \\
+202.80 \\
+224.01 \\
+236.72\end{array}$ \\
\hline
\end{tabular}

* Risk $=\mathbf{A}+\mathbf{P}+\mathbf{S}$. Average population risk of 100 corresponds to perinatal mortality rate of 33.58 per 1,000 births.

ing and using models which incorporate a larger number of factors.

The problem of specifying a prediction model involves more than the selection of the factors to be included. In addition we must decide whether to allow for any interaction among the effects of the various factors. The model shown in Table $I$ is presented as though the risk for any case is the sum of an age effect and a parity effect, tacitly assuming that there is no interaction ("synergism") between these two factors. If, for example, the risk of older primiparae were more than the sum of the high risk due to age and the high risk of the first birth, the model could be improved by including a separate factor value for this. To assess the importance of these interactions, we have experimented with a model which incorporates an age factor, a parity factor, and an additional factor for primiparity; for primiparae the estimated risk is the sum of three factor values, while for all others only two factor values are used. This experiment indicates that interaction is not important in evaluating the effects of age and parity on perinatal mortality.

The results of the experimental model are presented in Table III (opposite). Column (3) shows the cases in each parity-age combination during the survey week. Column (4) shows the corresponding observed number of deaths. We may compare the observed number of deaths with the number predicted by a simple age-parity model (column 5 ) and the number predicted by the more detailed model with the separate primiparity factor (column 6). The Table also shows (column 7) the number of deaths that would be predicted on the "naive" assumption that the perinatal mortality rate was the same (33 $\cdot 58$ per 1,000 births) in all age-parity groups.

Before appraising the overall agreement between the observed number of deaths and the two sets of predictions, we may note the results for older 
TABLE III

ANALYSIS OF INTERACTION EFFECTS OF MATERNAL AGE AND PARITY ON PERINATAL MORTALITY PREDICTED NUMBER OF DEATHS BY AGE AND PARITY

\begin{tabular}{|c|c|c|c|c|c|c|}
\hline \multirow[b]{2}{*}{$\begin{array}{l}\text { Parity } \\
\text { (1) }\end{array}$} & \multirow[b]{2}{*}{$\begin{array}{c}\text { Age (yrs) } \\
\text { (2) }\end{array}$} & \multirow[b]{2}{*}{$\begin{array}{l}\text { No. of Cases } \\
\text { (3) }\end{array}$} & \multirow[b]{2}{*}{$\begin{array}{l}\text { Average } \\
\text { Observed } \\
\text { Number of } \\
\text { Deaths } \\
\text { (4) }\end{array}$} & \multicolumn{3}{|c|}{ Predicted Number of Deaths } \\
\hline & & & & $\begin{array}{c}\text { Prediction } \\
\text { with No } \\
\text { Interaction } \\
\text { (5) }\end{array}$ & $\begin{array}{c}\text { Prediction } \\
\text { with Primiparae } \\
\text { Separated } \\
\text { (6) }\end{array}$ & $\begin{array}{l}\text { "Naive" } \\
\text { Prediction } \\
\text { (7) }\end{array}$ \\
\hline 0 & $\begin{array}{c}<20 \\
20- \\
25- \\
30- \\
35- \\
40-44 \\
\text { Others }\end{array}$ & $\begin{array}{r}841 \\
2,778 \\
1,791 \\
621 \\
208 \\
37 \\
8\end{array}$ & $\begin{array}{r}30 \cdot 00 \\
91 \cdot 11 \\
60 \cdot 15 \\
27 \cdot 51 \\
11 \cdot 71 \\
2 \cdot 65 \\
\cdot 88\end{array}$ & $\begin{array}{r}31 \cdot 06 \\
92 \cdot 72 \\
61 \cdot 00 \\
25 \cdot 06 \\
10.09 \\
2 \cdot 56 \\
\cdot 71\end{array}$ & $\begin{array}{r}29 \cdot 38 \\
91 \cdot 60 \\
60 \cdot 14 \\
27 \cdot 62 \\
10 \cdot 24 \\
2 \cdot 49 \\
.92\end{array}$ & $\begin{array}{r}28 \cdot 25 \\
93 \cdot 31 \\
60 \cdot 16 \\
20 \cdot 86 \\
6 \cdot 99 \\
1 \cdot 24 \\
\cdot 27\end{array}$ \\
\hline 1 & $\begin{array}{c}<20 \\
20- \\
25- \\
30- \\
35- \\
40-44 \\
\text { Others }\end{array}$ & $\begin{array}{r}132 \\
1,564 \\
2,025 \\
1,062 \\
364 \\
64 \\
4\end{array}$ & $\begin{array}{r}4 \cdot 49 \\
36 \cdot 41 \\
42 \cdot 43 \\
27 \cdot 59 \\
14 \cdot 68 \\
3 \cdot 85 \\
.40\end{array}$ & $\begin{array}{r}3 \cdot 33 \\
33 \cdot 90 \\
45 \cdot 28 \\
30 \cdot 43 \\
13 \cdot 39 \\
3 \cdot 69 \\
\cdot 31\end{array}$ & $\begin{array}{r}4 \cdot 99 \\
34 \cdot 49 \\
45 \cdot 14 \\
28 \cdot 97 \\
12.69 \\
3 \cdot 67 \\
.42\end{array}$ & $\begin{array}{r}4 \cdot 43 \\
52 \cdot 53 \\
68 \cdot 02 \\
35 \cdot 67 \\
12 \cdot 23 \\
2 \cdot 15 \\
\cdot 13\end{array}$ \\
\hline 2 & $\begin{array}{c}<20 \\
20- \\
25- \\
30- \\
35- \\
40-44 \\
\text { Others }\end{array}$ & $\begin{array}{r}5 \\
438 \\
944 \\
764 \\
412 \\
77 \\
11\end{array}$ & $\begin{array}{r}\cdot 64 \\
11 \cdot 39 \\
28 \cdot 95 \\
26 \cdot 23 \\
15 \cdot 00 \\
5 \cdot 69 \\
\cdot 64\end{array}$ & $\begin{array}{r}\cdot 15 \\
12 \cdot 05 \\
26 \cdot 61 \\
26 \cdot 35 \\
17 \cdot 55 \\
4 \cdot 88 \\
.92\end{array}$ & $\begin{array}{r}\cdot 22 \\
12 \cdot 43 \\
27 \cdot 01 \\
25 \cdot 68 \\
16.96 \\
4 \cdot 89 \\
1 \cdot 22\end{array}$ & $\begin{array}{r}\cdot 17 \\
14 \cdot 71 \\
31 \cdot 71 \\
25 \cdot 66 \\
13 \cdot 84 \\
2 \cdot 59 \\
\cdot 37\end{array}$ \\
\hline 3 & $\begin{array}{c}<20 \\
20- \\
25- \\
30- \\
35- \\
40-44 \\
\text { Others }\end{array}$ & $\begin{array}{r}111 \\
400 \\
465 \\
281 \\
67 \\
2\end{array}$ & $\begin{array}{r}-\overline{3 \cdot 13} \\
13 \cdot 15 \\
17 \cdot 32 \\
12 \cdot 11 \\
3 \cdot 53 \\
\cdot 64\end{array}$ & $\begin{array}{r}3 \cdot 30 \\
12 \cdot 15 \\
17 \cdot 05 \\
12 \cdot 59 \\
4 \cdot 40 \\
\cdot 17\end{array}$ & $\begin{array}{r}3 \cdot \overline{44} \\
12 \cdot 49 \\
16 \cdot 84 \\
12 \cdot 30 \\
4 \cdot 43 \\
\cdot 23\end{array}$ & $\begin{array}{r}3 \cdot 73 \\
13.44 \\
15.62 \\
9.44 \\
2.25 \\
.07\end{array}$ \\
\hline 4 & $\begin{array}{c}<20 \\
20- \\
25- \\
30- \\
35- \\
40-44 \\
\text { Others }\end{array}$ & $\begin{array}{r}738 \\
290 \\
509 \\
489 \\
172 \\
18\end{array}$ & $\begin{array}{r}\overline{1 \cdot 28} \\
12 \cdot 35 \\
23 \cdot 90 \\
26 \cdot 71 \\
12 \cdot 35 \\
1 \cdot 68\end{array}$ & $\begin{array}{r}1 \overline{1} .52 \\
11 \cdot 80 \\
23.91 \\
26.95 \\
13 \cdot 07 \\
1 \cdot 73\end{array}$ & $\begin{array}{r}1 \cdot \overline{56} \\
12 \cdot 02 \\
23 \cdot 65 \\
26 \cdot 41 \\
13 \cdot 14 \\
2 \cdot 24\end{array}$ & $\begin{array}{r}1 \cdot 28 \\
9 \cdot 74 \\
17 \cdot 10 \\
16 \cdot 42 \\
5 \cdot 78 \\
\cdot 60\end{array}$ \\
\hline
\end{tabular}

primiparae. It is clear that for these women (para- 0 , ages 35-39 and 40-44) both sets of predictions agree well with the observed value. We may conclude that the high risk of older primiparae is the sum of separate age and parity effects without any additional interaction effect. Comparing columns (5) and (6) with column (4) shows that both prediction models give results that agree closely with the observed numbers of deaths. In general the interaction model of column (6) gives slightly better predictions than the simpler model of column (5), but this is not always true. The no-interaction model accounts for $91 \cdot 1$ per cent. of the variation among the age-parity combinations, while the separated primiparae interaction model accounts for $\mathbf{9 4 \cdot 2}$ per cent.

Another measure of the agreement of the predicted and observed numbers of deaths is given by calculating $\chi^{2}$ values; a relatively low $\chi^{2}$ value would indicate that the differences between observed and predicted numbers could be due to chance, while a high value would indicate that the prediction models were inadequate. For both models the $\chi^{2}$ values are extremely low: $\chi^{2}=6 \cdot 59$ with 21 degrees of freedom for the no-interaction model, and $\chi^{2}=4.65$ with 15 degrees of freedom for the interaction model. The probability of obtaining such $\chi^{2}$ values by chance is greater than 99 . (In contrast, the naive prediction model has a $\chi^{2}$ value of $59 \cdot 54$ which, with 31 degrees of freedom, has a probability of less than 0.1 of occurring by chance.)

Including interaction effects can greatly increase the amount of calculation and the complexity of applying the results. In developing risk evaluation models, interaction effects will generally be ignored.

\section{SOME APPlications}

Risk evaluation models could assist in determining the care and advice that should be given to expectant mothers. An accurate assessment of risk would enable better allocation of beds in hospitals and National Health Service maternity homes (Feldstein, 1963, 
1965a). The current policy of the Ministry of Health was stated in the Cranbrook Report (1959). The committee recommended 100 per cent. hospitalization for all mothers of 35 years of age or more, all women aged 30 or more having their first child, and those who had had four or more children, or who had had a stillbirth. Although each of these groups has a high risk of perinatal mortality, the results of Table II show that this single factor approach is inadequate. Consider the advice that all women above 35 years of age be delivered in hospital. The Perinatal Mortality Survey showed that women between 35 and 39 had, in general, a perinatal mortality rate that was 36 per cent. above average. But from Table II we see that a para-1 in this age group and in Social Class I or II is actually below average in risk, the value being $172 \cdot 19-61 \cdot 80-19 \cdot 57=90 \cdot 82$ Even in Social Class III the risk for a woman of that age and parity is less than 10 per cent. above average. Another group recommended by Cranbrook for 100 per cent. hospital delivery is the woman over 30 having her first child; here again, if she is in the professional or managerial class and not above 35 years her risk is less than 2 per cent. above average.

There is of course a difference between perinatal mortality risk and the ability to benefit from hospital care. Certain types of perinatal deaths are more likely than others to be prevented by hospital delivery. We need only contrast intrapartum asphyxia and congenital malformation. Similarly, better antenatal care rather than mere hospital booking is appropriate for cases with high risk of antepartum death. Specific models will therefore be developed to assess the risk of perinatal mortality at different stages and from various causes. The doctor will therefore be able to plan a patient's care on the basis of a set of risk values. If possible, this will be supplemented by measures of the extent to which risk is decreased by hospital delivery.

I am grateful to several people for their contributions to this research: Dr Neville Butler, Dr Michael Dawkins, Prof. W. M. Gorman, and several colleagues at Nuffield College, for discussions; Miss Kathłeen Foley for valuable assistance in preparing the statistical calculations; the Oxford University Computing Laboratory for the use of its facilities; and The National Birthday Trust Fund for providing financial assistance and supplying the data of the Perinatal Mortality Survey.

This paper is part of a study of the operation and economics of the National Health Service, financed by grants from the Ministry of Health and the Health Information Foundation.

\section{REFERENCES}

Butler, N. R., and Bonham, D. G. (1963). "Perinatal Mortality".' Livingstone, Edinburgh.

Feldstein, M. S. (1963). Oxford Economic Papers. (1965a). Operational Research Quarterly, 16, 65. (1965b). J. roy. statist. Soc. (in press).

Johnston, J. (1963). "Econometric Methods", pp. 227-8. McGraw-Hill, New York.

Ministry of Health (1959). "Report of the Maternity Services Committee" (Cranbrook Report). H.M.S.O., London.

Suits, D. B. (1957). J. Amer. statist. Ass., 52, 548.

\section{APPENDIX}

\section{Binary Variable Multiple Regression Estimation OF FACTOR VALUES}

The factor values used for assessing perinatal mortality risk are derived from coefficients of a multiple regression equation in which all variables are binary. The method of calculation is explained in this Appendix (Suits, 1957; Johnston, 1963; Feldstein, 1965b).

For concreteness we consider a risk prediction model with only two factors, age and parity. Let age be divided into four groups and parity into three groups. Assume that each mother's age and parity are known. We may then express the relationship between perinatal mortality and the two factors as:

$$
Y_{t}=\sum_{i=I}^{6} \alpha_{i} X_{i t}+U_{t} \quad t=1,2, \ldots, T .
$$

where

$Y_{t}=1$ if birth $t$ results in a perinatal death. $=0$ if birth $t$ does not result in a perinatal death.

$X_{1 t}=1$ if mother is in age group I. $=0$ if mother is not in age group $I$.

$X_{2 t}=1$ if mother is in age group II. $=0$ if mother is not in age group II.

$X_{3 t}=1$ if mother is in age group III. $=0$ if mother is not in age group III.

$X_{4 t}=1$ if mother is in parity group 1 . $=0$ if mother is not in parity group 1.

$X_{5 t}=1$ if mother is in parity group 2 . $=0$ if mother is not in parity group 2 .

$X_{6 t}=1$ for all $t$. (This is used in calculation of constant term $\alpha_{8}$ ).

$U_{t}$ is an unobservable stochastic error term.

Note that for each factor the number of variables is one less than the number of sub-classes; although 
age is divided into four groups we use only three age variables. The omission is necessary to avoid singularity of the set of normal equations. No information is lost in this way. Since the four groups are mutually exclusive, if we know the values of $X_{1 t}$, $X_{2 t}$, and $X_{3 t}$ we also know whether or not the woman is in the fourth age group.

\section{REGRESSION ESTIMATES}

We may obtain estimates of the $\alpha \mathrm{s}$ by a least squares regression on the five explanatory variables. In the current case, this involves solving a set of six "normal equations" for the six unknown coefficients Because the variables are binary, the normal equations take a particularly simple form. Consider the typical term of a normal equation, $a_{i} \sum_{t=1}^{\mathrm{T}} X_{i t} X_{j t}$, where $a_{i}$ is the estimate of $\alpha_{i}$ and $i$ may or may not equal $j$. Since $X_{i t} X_{j t}=1$ if and only if $X_{i t}=1$ and $X_{j t}=1$ (i.e. if and only if the woman is in groups $i$ and $j), \sum_{t} X_{i t} X_{j t}$ is the number of women who are in both group $i$ and group $j$. For convenience, we shall write $\sum_{t} X_{i t} X_{j t}=n_{i j}$; thus $\sum_{t} X_{1 t} X_{5 t}=n_{1,5}$ is the number of women in age group $I$ and parity group 2 . It is obvious that if $i$ and $j$ refer to sub-classes of the same factor, and $i \neq j, n_{i j}=0$; for example, the number of women in both age group I and age group II $\left(n_{1,2}=0\right)$. If $i=j, \sum_{t}^{\sum} X_{i t} X_{j t}=\sum_{t}^{\sum} X^{2}{ }_{i t}=n_{i}$, the number of women in sub-class $i$. Finally, the terms $\sum_{t} X_{i t} Y_{t}$ are equal to the number of perinatal deaths occurring to mothers in sub-class $i$; we shall write this as $d_{i}$ and denote the total number of deaths as $d_{6}$. The normal equations can thus be written as:

$$
\begin{aligned}
& a_{1} n_{1} \quad+a_{4} n_{1,4}+a_{5} n_{1,5}+a_{6} n_{1}=d_{1} \\
& a_{2} n_{2} \quad+a_{4} n_{2,4}+a_{5} n_{2,5}+a_{6} n_{2}=d_{2} \\
& a_{3} n_{3} \quad+a_{4} n_{3,4}+a_{5} n_{3,5}+a_{6} n_{3}=d_{3} \\
& a_{1} n_{1,4}+a_{2} n_{2,4}+a_{3} n_{3,4}+a_{4} n_{4} \quad+a_{6} n_{4}=d_{4} \\
& a_{1} n_{1,5}+a_{2} n_{2,5}+a_{3} n_{3,5} \quad+a_{5} n_{5}+a_{6} n_{5}=d_{5} \\
& a_{1} n_{1}+a_{2} n_{2}+a_{3} n_{3} \quad a_{4} n_{4}+a_{5} n_{5} \quad+a_{6} n_{6}=d_{6}
\end{aligned}
$$

From this it is clear that the normal equations can be written directly from a list of the number of deaths in each sub-class $\left(d_{1}\right.$ to $\left.d_{6}\right)$ and the information contained in a two-way table classifying women by age and parity.

This method can be extended to a large number of factors. In every case we can write the normal equations directly from a set of two-way tables; if there are $k$ factors, we need $k(k-1) / 2$ two-way tables.

\section{HETEROSKEDASTICITY}

The usual method of calculating least square estimates is based on the assumption that the stochastic error term of every observation has the same variance. This assumption is untenable in the present case. The variance of $U_{t}$ is:

$$
\sum_{i=1}^{6} \alpha_{i} X_{i t}\left(1-\sum_{i=1}^{6} \alpha_{i} X_{i t}\right)
$$

Ordinary least squares estimates are unbiased even when the error terms are not of constant variance. The efficiency of the estimates could be improved by using the ordinary least squares estimates of the $\alpha$ s to calculate the variance of each $U_{t}$ and then using generalized least squares estimation. With a sample of nearly 17,000, the gain in efficiency does not justify the additional calculations.

\section{Factor VAlues}

To obtain factor values from the estimated regression coefficients, we first reintroduce the excluded categories of age and parity and assign to each coefficient the value zero. The constant term is then eliminated by dividing it by the number of factors and adding the quotient to each coefficient. Finally the scale of values is changed so that the mean risk value corresponds to a score of 100 ; this is done by dividing each coefficient by one per cent. of the true mean risk $\left(\cdot 01 \bar{y}=3 \cdot 358.10^{-4}\right)$.

Thus the factor value corresponding to the first age group $=$

$$
\frac{a_{1}+\left(a_{6}\right) / 2}{3 \cdot 358} \cdot 10^{4} \text {. }
$$

